\title{
Protein profiling and pseudo-parallel reaction monitoring to monitor a fusion-associated conformational change in hemagglutinin
}

\author{
Khanh K. Nguyen ${ }^{1} \cdot$ Stephanie Thurmond ${ }^{2} \cdot$ Rong Hai $^{2} \cdot$ Joseph C. Genereux ${ }^{1}$ (D) \\ Received: 3 April 2019 / Revised: 8 May 2019 / Accepted: 14 May 2019 / Published online: 28 June 2019 \\ (C) Springer-Verlag GmbH Germany, part of Springer Nature 2019
}

\begin{abstract}
Influenza infection requires viral escape from early endosomes into the cytosol, which is enabled by an acid-induced irreversible conformational transformation in the viral protein hemagglutinin. Despite the direct relationship between this conformational change and infectivity, label-free methods for characterizing this and other protein conformational changes in biological mixtures are limited. While the chemical reactivity of the protein backbone and side-chain residues is a proxy for protein conformation, coupling this reactivity to quantitative mass spectrometry is a challenge in complex environments. Herein, we evaluate whether electrophilic amidination coupled with pseudo-parallel reaction monitoring is an effective label-free approach to detect the fusion-associated conformational transformation in recombinant hemagglutinin (rHA). We identified rHA peptides that are differentially amidinated between the pre- and post-fusion states, and validated that this difference relies upon the fusionassociated conformational switch. We further demonstrate that we can distinguish the fusion profile in a matrix of digested cellular lysate. This fusion assay can be used to evaluate fusion competence for modified HA.
\end{abstract}

Keywords Protein conformation · Protein amidination · Mass spectrometry · Parallel reaction monitoring · Viral fusion . Hemagglutinin

\section{Introduction}

Influenza virus is a major cause of respiratory disease, causing $>300,000$ deaths in a typical year, millions to tens of millions of deaths in pandemic years, and extensive loss of economic activity [1]. An obligate step in viral infection is fusion of the

Published in the topical collection Young Investigators in (Bio-)Analytical Chemistry with guest editors Erin Baker, Kerstin Leopold, Francesco Ricci, and Wei Wang.

Electronic supplementary material The online version of this article (https://doi.org/10.1007/s00216-019-01921-z) contains supplementary material, which is available to authorized users.

Khanh K. Nguyen and Stephanie Thurmond are co-first authors.

Rong Hai

ronghai@ucr.edu

Joseph C. Genereux

josephg@ucr.edu

1 Department of Chemistry, University of California Riverside, 501 Big Springs Rd., Riverside, CA 92521, USA

2 Department of Plant Pathology \& Microbiology, University of California Riverside, Riverside, CA 92521, USA viral membrane with the endosomal membrane, which allows for release of the viral RNA-polymerase complex (RNPs) into the host cytosol. This fusion is driven by an acid-induced conformational change in the viral coat protein hemagglutinin (HA). Because fusion is essential for infection, fusion inhibition has been an intensively pursued approach to block influenza infection using small molecules. Although recent studies have elucidated the biochemical mechanism of HA-mediated fusion $[2,3]$, the sequence dependence and particularly intracellular factors that govern HA fusion competence are still unclear. Largely, this is due to a lack of tools to readily characterize HA conformational changes inside the cell.

Mature HA (cleaved to two domains: HA1 and HA2) mediates viral endocytosis into the cell through engagement of the sialic acid receptor by the HA1 domain. Under the acidic conditions of the early endosome, HA undergoes a global conformational change [4], including extensive remodeling of both HA1 and HA2 domains. As a result, an $\mathrm{N}$-terminal region of HA2, termed the fusion peptide, is exposed. The fusion peptide embeds into the endosomal membrane, promoting fusion with the viral membrane and subsequent release of the viral genome into the cytosol. The most dramatic structural change takes place over the HA2 
region in the stalk domain near the $\mathrm{C}$-terminus; acidification and conversion to the post-fusion state lead to a substantial increase in solvent exposure in this region. Given the large change in solvent engagement over the entirety of HA, we hypothesized that profiling reactions would be sensitive to the fusion event.

Hence, we set out to develop a label-free, targeted approach to interrogate HA fusion competence. The gold standard for profiling protein conformation is hydrogendeuterium exchange (HDX) [5], which has been successfully applied to fully characterize solvent exposure throughout HA in both pre- and post-fusion states [2]. HDX has several limitations, however, including incompatibility with biologically complex matrices, the requirement for rapid, highresolution separation, and usually high nanogram to microgram levels of sample. To overcome these challenges, oxidative and electrophilic labeling approaches have been taken to footprint water accessibility on protein surfaces, both in buffer and in complex media [6-10]. Among oxidative approaches, SPROX employs peroxide to oxidize methionine residues $[9,11]$, while FPOP generates oxidizing radicals through photolysis [12-15]. Electrophilic approaches include targeting lysine with NHS esters $[16,17]$, oxyimidates, and thioimidates [18-20], and targeting glutamate and aspartate with glycine ethyl ester [21-23]. Thioimidate reagents are notable in that they are cell-penetrable, selectively label an abundant amino acid (lysine), provide a homogenous reaction product allowing straightforward spectral assignment, promote ionization during electrospray, and do not modify residue charge, which can itself alter protein conformation [24].

Previously, thioimidates have been applied to discover changes in intracellular protein conformation using datadependent analysis, yielding similar performance to SPROX. However, when targeting specific modifications, greater sensitivity and robustness can be achieved by using targeted, data-independent methods. Although being required to assay for a specific peptide, as opposed to the best performing peptides in an entire protein, sharply constrains target peptide choice, multiple reaction monitoring (MRM) and parallel reaction monitoring (PRM) have proven effective for quantifying PTMs [25, 26] and adduct sites [27]. Hence, we considered that electrophilic profiling by Smethylthioacetimidate (SMTA), followed by reaction monitoring, might be an effective strategy to identify pre- and post-fusion HA conformational states. Herein, we implement a targeted MS/MS technique of pseudo-parallel reaction monitoring to quantify labeling of the pre- and post-fusion HAs. We find that SMTA efficiently labels HA, distinguishing the pre- and post-fusion states, and that we can measure this difference using reaction monitoring. This will enable the further development of assays to assess HA viral fusion competence.

\section{Materials and methods}

\section{Materials}

Sodium phosphate, sodium chloride, HEPES, Tris, MS-grade methanol, MS-grade acetonitrile, and chloroform were obtained from Fisher (Pittsburgh, PA, USA). Tissue-culture grade dimethyl sulfoxide was obtained from Corning (Corning, NY, USA). Urea, formic acid, TCEP, and iodoacetamide were obtained from Acros (a division of Fisher). Sodium citrate was obtained from VWR (Radnor, PA, USA). Imidazole was obtained from Sigma (Burlington, VA, USA). Phosphatebuffered saline (PBS; $10 \mathrm{mM}$ phosphate, $150 \mathrm{mM}$ sodium, $\mathrm{pH}$ 7.4) was obtained from GE Healthcare (Chicago, IL, USA).

\section{Preparation and purification of recombinant hemagglutinins}

HEK293T was obtained from ATCC (Manassas, VA, USA). The cells were cultured in complete media containing DMEM (Corning) supplemented with 10\% FBS (Seradigm, a division of VWR), $1 \%$ L-glutamine (Corning), and $1 \%$ penicillin streptomycin (Corning). HA was prepared as previously described [28]. Briefly, PR8HA-6xHistag (strain A/Puerto Rico/8/1934 H1N1) expressing plasmid was transfected to HEK293T cells by the PEI transfection method. After $72 \mathrm{~h}$, the cultured media were cleared by low speed centrifugation $(3500 \mathrm{rpm}, 20 \mathrm{~min}$, $4{ }^{\circ} \mathrm{C}$ ) and the HA was purified by His6 Ni Superflow resin (Clontech) overnight at $4{ }^{\circ} \mathrm{C}$. The resin media were passed through $10 \mathrm{~mL}$ polypropylene columns (Qiagen, Germantown, MD, USA). The retained resin was washed 4 times with wash buffer $\left(50 \mathrm{mM} \mathrm{NaH} \mathrm{PO}_{4}, 30 \mathrm{mM} \mathrm{NaCl}\right.$, $20 \mathrm{mM}$ imidazole, $\mathrm{pH}$ 8.0). The protein was eluted with elution buffer $\left(50 \mathrm{mM} \mathrm{NaH}{ }_{2} \mathrm{PO}_{4}, 30 \mathrm{mM} \mathrm{NaCl}, 250 \mathrm{mM}\right.$ imidazole, $\mathrm{pH}$ 8.0). The eluate was concentrated using an Amicon $10 \mathrm{kDa}$ MWCO spin column (Merck Millipore, Burlington, MA, USA) and dialyzed 4 times with PBS and quantified by Thermo Nanodrop 3.0 (Thermo, Waltham, MA, USA). Purity was evaluated by Silver Stain [29].

\section{Acid-induced activation of recombinant HA}

PR8 was chosen as the HA wild-type model for the study. Purified recombinant PR8 HA was diluted in PBS buffer. To pre-cleave the precursor HA0 to HA1 and HA2, TPCK-treated trypsin was added to the protein at a ratio of 10:1 (protein-toprotease) and incubated with $600 \mathrm{rpm}$ shaking at $37{ }^{\circ} \mathrm{C}$ for 5 min. Pre-cleavage was quenched with $1 \mathrm{mM}$ PMSF (Sigma), which remains in the sample solution through later steps. The $\mathrm{pH}$ of PR8 HA solution was brought to $\mathrm{pH} 4.9$ by adding citrate buffer at $\mathrm{pH} 3.0$ to a final citrate concentration of $7.0 \mathrm{mM}$. The acidified HA was incubated at ambient 
temperature for $3 \mathrm{~h}$, then brought to $\mathrm{pH} 8.0$ by $20 \mathrm{mM}$ phosphate $\mathrm{pH}$ 11.00. The neutral control sample was treated in the same manner with citrate $\mathrm{pH} 7.4$ to a final citrate concentration of $7.0 \mathrm{mM}$. Both acidified and neutral samples were brought to equal volumes by PBS. The fusion inhibitor [30] arbidol-HCl (Fisher) was added as indicated in DMSO following precleavage at a concentration of $400 \mu \mathrm{M}$ and incubated for $30 \mathrm{~min}$ at ambient temperature prior to acidification. Control samples received $4 \%$ DMSO vehicle alone.

\section{Trypsin susceptibility of acid-induced HA}

The treated HA above was incubated at $37{ }^{\circ} \mathrm{C}$ for $3 \mathrm{~h}$ to deactivate PMSF, then was digested with TPCK-trypsin (Sigma) at 5:1 (protein:protease ratio) for $30 \mathrm{~min}$ at $37{ }^{\circ} \mathrm{C}$, shaken at $600 \mathrm{rpm}$ [31]. Immediately after being digested, the samples were denatured and reduced in $1 \mathrm{X}$ Laemmli buffer (12\% SDS $(w / v), 0.06 \%$ bromophenol blue $(w / v), 47 \%$ glycerol $(v / v)$, and $60 \mathrm{mM}$ Tris $\mathrm{pH} 6.8)$ and $20 \mathrm{mM}$ DTT. The denatured protein was boiled at $100{ }^{\circ} \mathrm{C}$ for $5 \mathrm{~min}$. The digest was separated on $12 \%$ reducing SDS-PAGE gel for silver staining.

\section{SMTA labeling of recombinant HA}

SMTA was prepared as the hydrogen iodide salt from thioacetamide (Sigma) and methyl iodide (Sigma), as previously described [18], and aliquots stored under $\mathrm{Ar}$ at $-80^{\circ} \mathrm{C}$. Aliquots were freshly dissolved prior to labeling in $25 \mathrm{mM}$ HEPES, $50 \mathrm{mM} \mathrm{NaCl} \mathrm{pH} 7.4$ at $200 \mathrm{mM}$ SMTA, which was then neutralized with sodium hydroxide. SMTA solution was added to PR8 HA samples, mixed well and let sit for $30 \mathrm{~min}$ at ambient temperature. The reaction was quenched by methanol-chloroform precipitation, by adding 4 equivalents methanol, 1 equivalent chloroform, and 3 equivalents water with vortexing after each addition, followed by sedimentation of protein to the interphase at $10,000 \times g$ for $5 \mathrm{~min}$. The aqueous layer was removed and the protein pellet washed well with methanol and air-dried.

\section{Sample preparation for mass spectrometry}

Air-dried protein pellets were solubilized in freshly prepared $9 \mathrm{M}$ urea in $50 \mathrm{mM}$ Tris $\mathrm{pH}$ 8.0. Ten millimolar aqueous TCEP was added to reduce the disulfide bonds for $30 \mathrm{~min}$ in the dark at room temperature. Five millimolar aqueous iodoacetamide was added to alkylate the sulfhydryl groups for $15 \mathrm{~min}$ in the dark at room temperature. The solutions were diluted with $50 \mathrm{mM}$ Tris $\mathrm{pH} 8.0$ to $2 \mathrm{M}$ urea and digested with sequencing grade porcine trypsin (Thermo) or Glu-C (Thermo) at a ratio of 20:1 protein-to-protease for 18 to $24 \mathrm{~h}$ at $37{ }^{\circ} \mathrm{C}$, shaken at $600 \mathrm{rpm}$. After digestion, the samples were acidified with $5 \%$ formic acid and debris eliminated at $21,100 \times \mathrm{g}$ for $30 \mathrm{~min}$.

\section{Preparation of complex mixtures containing digested HA}

HEK293T cells were harvested by scrapping in PBS and lysed in RIPA buffer ( $50 \mathrm{mM}$ Tris pH 7.5, $150 \mathrm{mM} \mathrm{NaCl}, 1 \%$ Triton $\mathrm{X}-100,0.5 \%$ deoxycholate, $0.1 \% \mathrm{SDS}$ ) or by freeze-thaw in PBS. The lysate concentration was quantified by Bradford assay (Bio-rad, Hercules, CA, USA) with the measurement by Varian Cary $60 \mathrm{UV} / \mathrm{Vis}$ spectrophotometer (Agilent, Santa Clara, CA, USA). The protein was precipitated by methanol-chloroform precipitation and prepared as digested peptides similar to the above description. Digested peptides from either acidified or neutral as described above was spiked in lysate at $10 \%(w / w)$. One microgram lysate was analyzed by pseudo-PRM in the LTQ Orbitrap Velos Pro (Thermo).

\section{Data-dependent analysis of SMTA-labeled PR8 HA}

Digest was injected from the autosampler of an Easy-nLC 1000 to the trapping column containing a Kasil frit and 2-cm $5 \mu \mathrm{m} \mathrm{C} 18$ resin (Phenomenex). High salt concentration was removed by washing with buffer A through the waste line. The analytical column is a pulled 5 um tip packed with 15to $20-\mathrm{cm} 3 \mu \mathrm{m} \mathrm{C} 18$ resin (Phenomenex, Torrance, CA, USA). The peptides were injected directly onto the trapping column at a flow rate of $5.0 \mu \mathrm{L} / \mathrm{min}$ and separated on the analytical column at a flow rate of $500 \mathrm{~nL} / \mathrm{min}$. Buffer A was $5 \%$ acetonitrile, $0.1 \%$ formic acid, and buffer B was $80 \%$ acetonitrile, $0.1 \%$ formic acid. The gradient conditions were as follows: 0 5 min: 1-7\%B; 5-95 min: 7-55\%B; 95-115 min: 55-100\%B; 115-120 min: $100 \% \mathrm{~B} ; 120-125 \mathrm{~min}: 100-1 \% \mathrm{~B} ; 125-$ $145 \mathrm{~min}: 1 \% \mathrm{~B}$. The eluate was sprayed at $3.0 \mathrm{kV}$ and the ion transfer tube maintained at $275{ }^{\circ} \mathrm{C}$. The mass spectrometer (LTQ Orbitrap Velos Pro) precursor scan was acquired with the AGC set to $10^{5}$ and 50 ms maximum injection time. In all data acquisition strategies, MS2 scans were acquired by CID at a normalized collision energy set to $35 \mathrm{kV}$.

\section{Targeted library generation}

Data-dependent acquisition of MS/MS spectra with the linear ion trap in the LTQ Orbitrap Velos Pro were performed with the following settings: MS/MS on the 10 most intense ions per precursor scan, dynamic exclusion repeat count, 1 , repeat duration, $30 \mathrm{~s}$; exclusion list size, 500; and exclusion duration, $5 \mathrm{~s}$. The raw data was extracted using Raw Converter to MS1 and MS2 spectral files. These files were searched against a database of the PR8 HA sequence and its reversed sequence by the ProLucid algorithm in the IP2 software suite (Integrated Proteomics, San Diego, CA) [32]. The database 
was supplemented with forward and reverse (decoy) sequences for 400 common contaminants (e.g., keratins, immunoglobulins, albumen). The precursor mass tolerance was set to $3000.0 \mathrm{~m}$-amu, and the fragment mass tolerance was set to $600.0 \mathrm{ppm}$. The search space included up to 3 missed cleaved tryptic peptides. Carbamidomethylation $(+57.02146)$ of cysteine was considered as a static modification. Amidination of lysine $(+41.02655)$ was permitted as a differential modification. Peptide candidates were filtered using DTASelect for less than $1 \%$ false positive peptides [33].

\section{Pseudo-PRM analysis}

From data-dependent analysis, the precursors were chosen such that their spectral counts are $>3$ and they are fully tryptic peptides (Table 1). From each precursor, the 3 most intense fragments were chosen for monitoring. The peptides were injected directly to the trapping column at a flow rate of $5.0 \mu \mathrm{L} / \mathrm{min}$ and separated on the analytical column at a flow rate of $350 \mathrm{~nL} / \mathrm{min}$. Buffer A was $5 \%$ acetonitrile, $0.1 \%$ formic acid, and buffer B was $80 \%$ acetonitrile, $0.1 \%$ formic acid. The gradient conditions were as follows: $0-1 \mathrm{~min}: 1-7 \% \mathrm{~B}$; $1-$ 59 min: 7-35\%B; 59-64 min: 35-100\%B; 64-69 min: 100\%B; 69-74 min: 100-1\%B; 74-94 min: 1\%B. The monitoring time for each peptide was $10 \mathrm{~min}$. In the linear ion trap, the precursor scan was acquired at normal resolution, with the AGC set to $10^{4}$ and $50 \mathrm{~ms}$ maximum injection time and isolation width of $1.0 \mathrm{~m} / \mathrm{z}$. In the FT Orbitrap, the precursor scan was acquired at a resolution of 15,000 , with the AGC set to $5 \times 10^{4}$, isolation width of $1.0 \mathrm{~m} / \mathrm{z}$, and $25 \mathrm{~ms}$ maximum injection time. The three most intense product ions were chosen for quantification. The integration of each transition was measured from the extracted ion chromatogram from Xcalibur and summed to obtain the total integration of each peptide. The $\mathrm{m} / \mathrm{z}$ windows used to extract the transitions for quantification in the linear ion trap and Orbitrap are $4 \mathrm{~m} / \mathrm{z}$ and $0.2 \mathrm{~m} / \mathrm{z}$, respectively. For each peptide, the evaluation of differential amidination between acidified and neutral conditions of HA was calculated as integration of modified peptide/integration of unmodified peptide.

\section{Multiple reaction monitoring}

MRM was performed on a Thermo TSQ Vantage with EasynLC II. The digest was injected (Easy-nLC II) onto a C18

Table 1 Peptide sequences for reaction monitoring

\begin{tabular}{llll}
\hline Peptide & Lysine & Sequence (amidination site marked K) & Charge state \\
\hline 1 & K 62 & R.LKGIAPLQLGK & $2+$ \\
2 & K 170 & R.NLLWLTEKEGSYPK & $2+$ \\
3 & K 394 & K.STQNAINGITNKVNTVIEK & $2+$ \\
4 & K 459 & R.TLDFHDSNVKNLYEK & $3+$ \\
\hline
\end{tabular}

column and washed using a similar trapping set-up as described above. Buffer A was $0.1 \%$ formic acid, and buffer B was $100 \%$ acetonitrile, $0.1 \%$ formic acid. The peptides were injected onto the trapping column at a flow rate of $2.50 \mu \mathrm{L} /$ min and separated on the analytical column at a flow rate of $230 \mathrm{~nL} / \mathrm{min}$. The gradient conditions were as follows: 0 1 min: 0-7\%B, 1-46 min: 7-33\%B, 46-47 min: $33-80 \% \mathrm{~B}$, 47-77 min: 80-90\%B. Trapping and analytical columns were equilibrated before every analysis. The elution time window set for each peptide was $6 \mathrm{~min}$. The spray voltage was set at $1.8 \mathrm{kV}$ and the discharge current was $4.0 \mu \mathrm{A}$ for all 3 quadrupoles. Collision energies were calculated with the following formula: $\mathrm{CE}=0.03 \times($ precursor $\mathrm{m} / \mathrm{z})+2.905$ for $2+$ charge ions and $\mathrm{CE}=0.038 \times($ precursor $m / z)+2.281$ for $3+$ charge ions. The Q1 and Q3 peak width (FWHM) was set to 0.70 and 0.80 , respectively. The cycle time was set to $800 \mathrm{~ms}$. Each peptide was integrated directly from its extracted ion chromatogram on Xcalibur.

\section{Statistical analysis}

Statistical analysis was performed in Excel. To compare the amidination profile between acidified and neutral conditions, we employed Student's $t$ test with the $p$ value set to 0.05 . For the comparison of multiple treatments, one-way ANOVA was employed with the alpha factor set to 0.05 , followed by Tukey's test. The sample size is indicated in the figure captions for each analysis. All data are expressed as means \pm standard deviations.

\section{Results and discussion}

\section{Generation of a library of amidinated HA peptides}

We chose PR8 HA (strain A/Puerto Rico/8/1934 H1N1) as our nominal "wild-type" HA, as this subtype's structure and fusion has been widely studied [34]. To increase recombinant PR8 yield by allowing secretion, the $\mathrm{C}$-terminal trimerization and membrane pass regions were replaced with a bacterial foldon trimerization domain $[35,36]$. This form has been validated to form PR8 HA trimers that still undergo aciddependent fusion, as demonstrated by protease susceptibility following acidic incubation [31]. We optimized cleavage of full-length HA (HA0) to mature HA1/HA2 by brief TPCK trypsinolysis (see Electronic Supplementary Material (ESM) Fig. S1A). The two bands for HA2 represent glycoforms, as confirmed by coalescence upon PNGase treatment (data not shown). Furthermore, citrate acidification of mature HA1/ HA2 renders the protein more sensitive to further tryptic degradation (Fig. 1a; lanes 3,4) as opposed to the mature protein in PBS (lanes 1,2) or treated with an isotonic neutral citrate buffer (Fig. 1a; lanes 5, 6). The tryptic sensitivity validates that 
Fig. 1 SMTA labeling of pre- and post-fusion rHA. Silver stain of SDS-PAGE separated recombinant PR8 HA (rHA), demonstrating trypsin susceptibility following acid-induced fusion. rHA subjected to brief trypsin precleavage (1:10 w/w TPCKtreated trypsin in PBS for $5 \mathrm{~min}$., $37^{\circ} \mathrm{C}, 600 \mathrm{rpm}$ ) was incubated in either acidic or neutral citrate buffer. Afterwards, all samples were brought to $\mathrm{pH} 8.0$, followed by trypsin digestion at $37^{\circ} \mathrm{C}$ for $30 \mathrm{~min}$. as indicated. Dagger symbol indicates small degradation products. Asterisk indicates residual protein from the media purification of HA, presumably bovine serum albumen. Flow chart for HA pre-cleavage, fusion, neutralization, and SMTA labeling. Structures are of H3N2 from PDB 1HA0 [37], 3HMG [38], and 1HTM [39] and visualized in NGL viewer [40]. Reaction mechanism for SMTA modification of the lysine amine. At neutral or greater $\mathrm{pH}$, deamination to the imide is disfavored, driving amidination as shown [24]

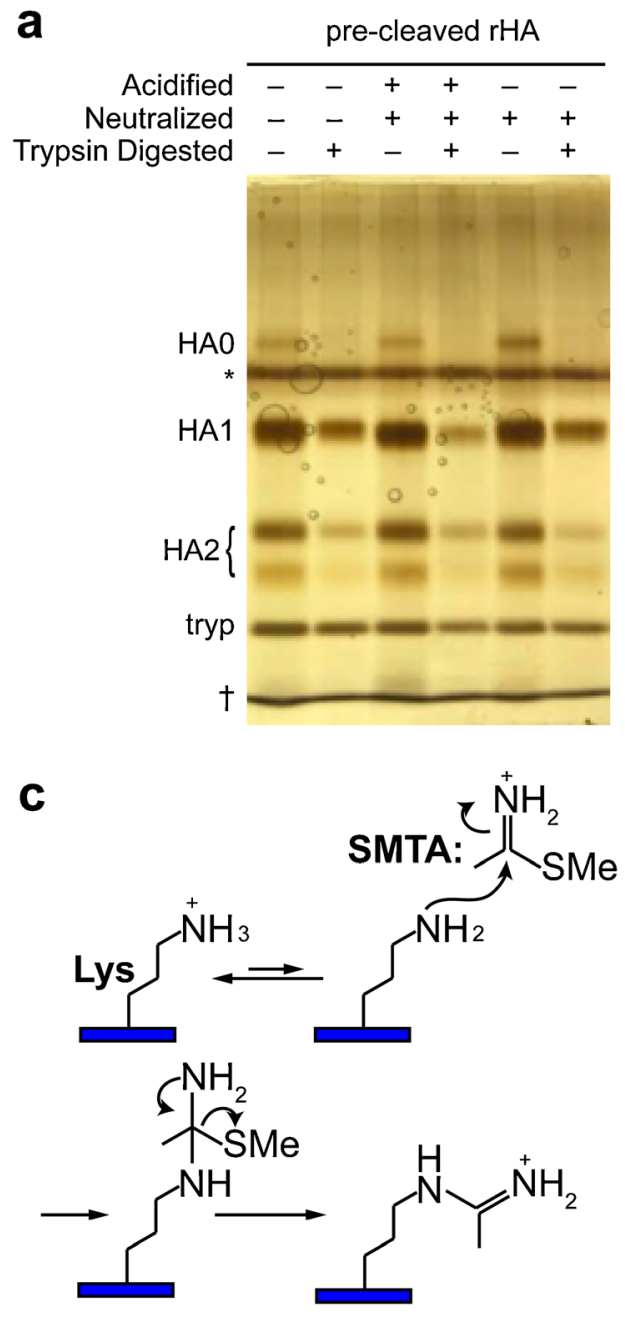

acidification promotes the conformational change to the postfusion state.

PR8 HA contains 37 lysine residues. To determine their amidination profile, we prepared PR 8 HA in both the preand post-fusion states and treated each with $20 \mathrm{mM}$ SMTA for $30 \mathrm{~min}$ at pH 8.0 (Fig. 1b). SMTA selectively amidinates lysine residues as this $\mathrm{pH}$ [24] (Fig. 1c). The reaction was quenched by chloroform-methanol precipitation, and the protein reduced, alkylated, and digested by either Glu-C or trypsin. Peptide sequences were determined by data-dependent LC-MS/MS. Qualitatively similar results in peptide identifications were observed for both pre- and post-fusion HA; hence, the following summarizes what was observed for the post-fusion HA. With trypsin modification, we observed 75$85 \%$ coverage of the protein (theoretical digest yields $86 \%$ coverage by peptides with between 5 and 30 residues long), with 0 lysines observed only with the modification, 9 lysines observed solely without the modification, and 25 lysines observed both with and without amidination (ESM Fig. S1B). By contrast, Glu-C digestion yielded $60-65 \%$ coverage of the

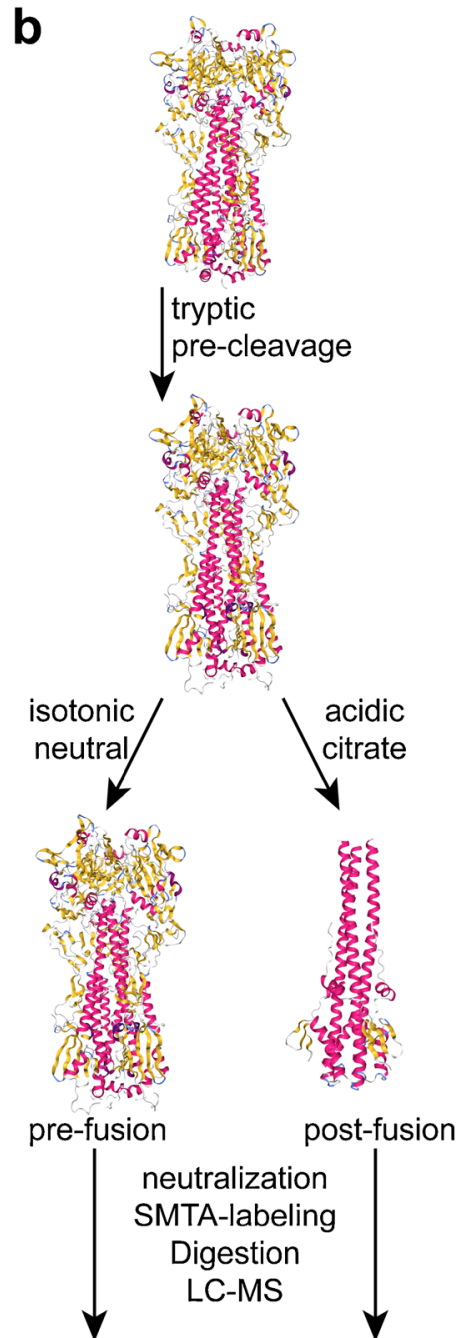

protein (theoretical digest yields $68 \%$ coverage by peptides between 5 and 30 residues long), with 0 lysines observed solely with the modification, 14 lysines observed solely without the modification, and 12 lysines observed both with and without amidination (ESM Fig. S1B). These results are consistent with previous findings that Glu-C yields peptides with poorer chromatographic profile, greater variability in digestion, and up to a threefold drop in unique peptide identifications [41]. Furthermore, the high density of Glu sites in the HA2 region inherently limits the coverage that can be obtained with this protease. Hence, we moved forward with trypsin, despite its inability to cleave amidinated lysine [19]. Interestingly, we found lysine amidination to be distributed throughout the protein sequence, indicating that the PR8 HA is accessible to SMTA across all domains (ESM Fig. S1C). Labeling does not appear to be saturating, as although some lysines were never observed to be modified, and other lysines are identified from peptide-spectral matches in either the modified or unmodified state, there are no lysines that we only observed to be amidinated. 


\section{Pseudo-PRM quantification of fusion-dependent HA amidination}

To identify peptides that could serve as markers of lysine amidination, we evaluated the tryptic library ( 3 runs) for peptides that met the following criteria [42]: (1) robustness of identification, with $\geq 3$ spectral counts in each run; (2) fully tryptic; (3) no missed cleavage except for at the amidination site; (4) containing lysines that were identified as both modified and unmodified, indicating that there is a dynamic range of modification; (5) lacking methionine; (6) no K/R within 2 amino acids of the cleavage site (except for -1 of course); and (7) charge state of either 2 or 3 . We identified 4 amidinated peptides that were worth further consideration based on these a
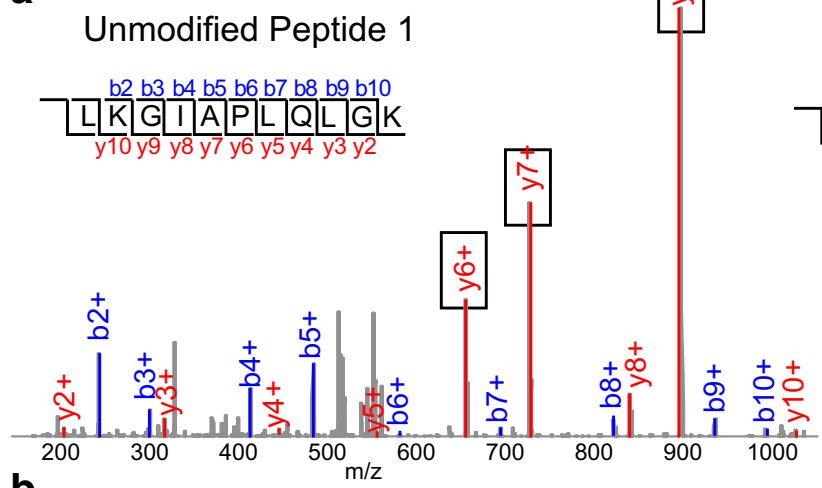

b
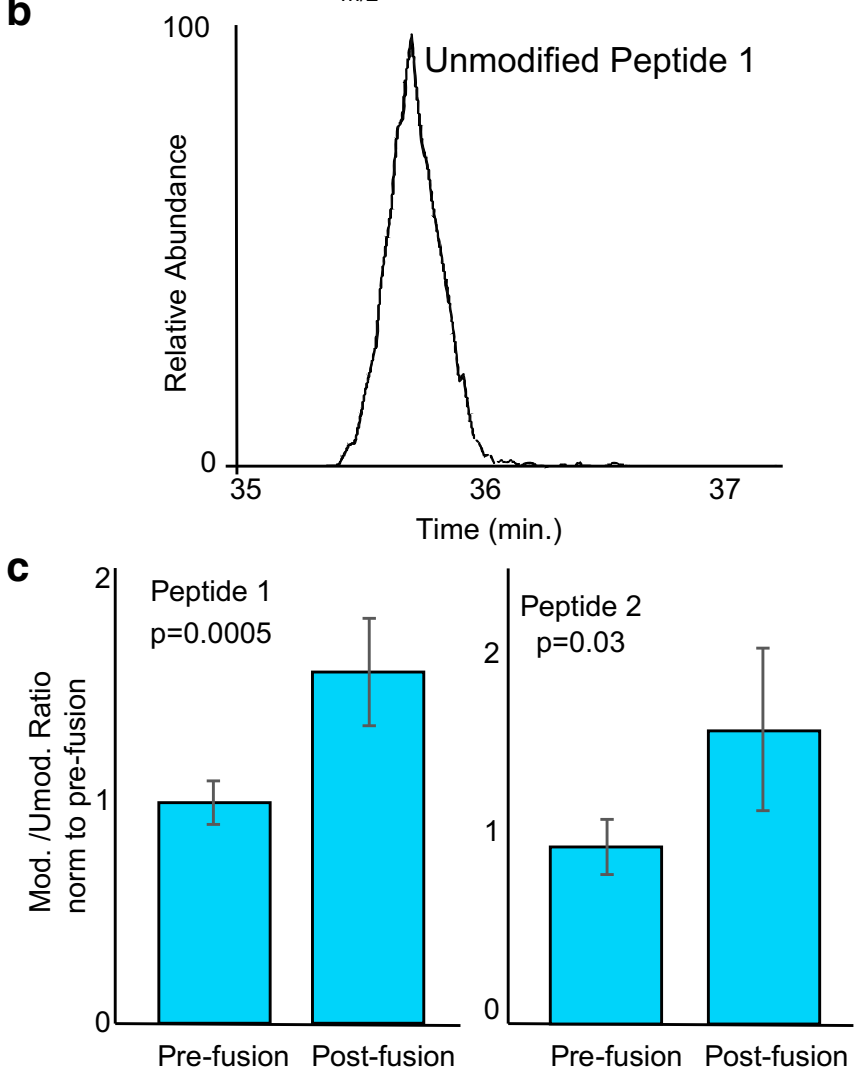

Fig. 2 Differential amidination of Peptides 1-4 by SMTA. CID fragmentation spectra collected on the LTQ for unmodified and amidinated Peptide 1 during DDA analysis of acidified, SMTA-labeled rHA digests prepared as in Fig. 1b. Identified b/y ions are indicated above and below the peptide sequence. Scan ranges were determined by the instrument. The transitions chosen for MRM, pseudo PRM and PRM analysis are indicated by boxes. Extracted ion chromatograms for unmodified and amidinated Peptide 1 analyzed during pseudo PRM in a LTQ Velos ion trap, summed from transitions indicated in Fig. 2a. Pseudo-
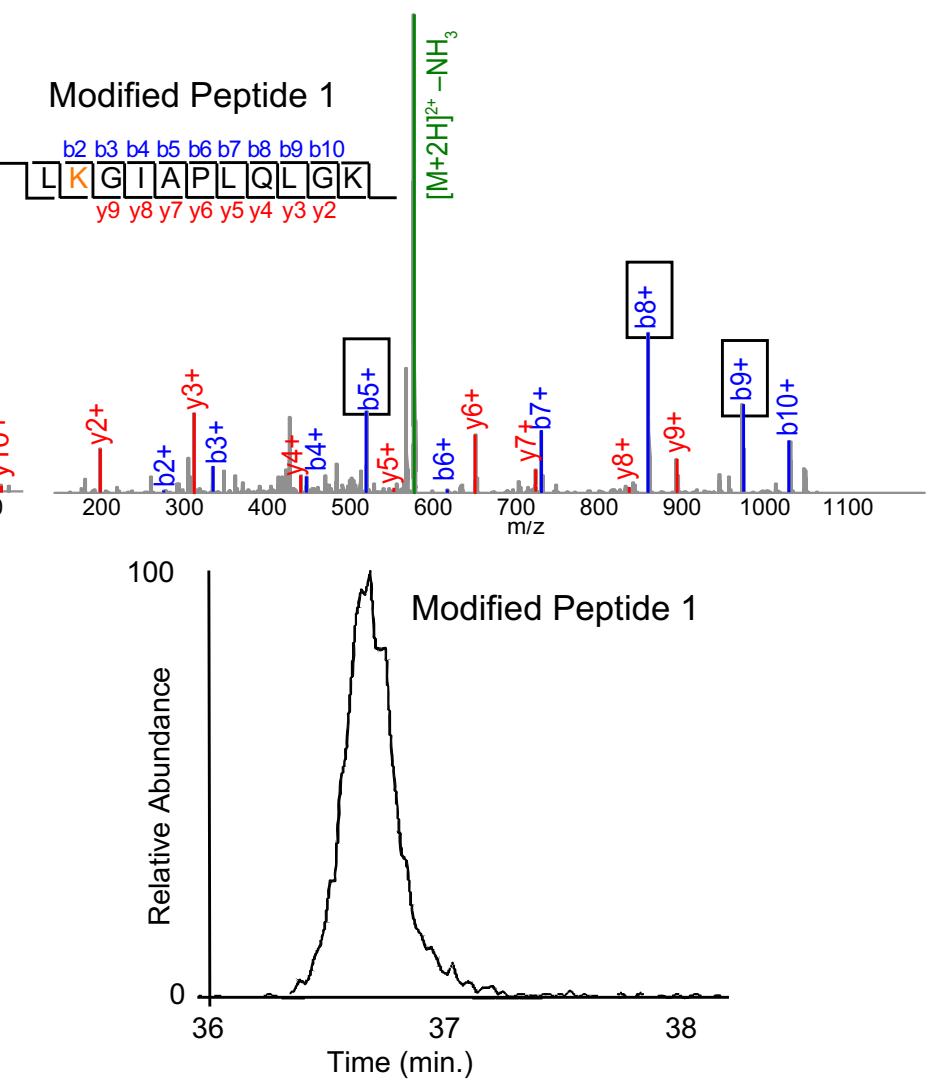

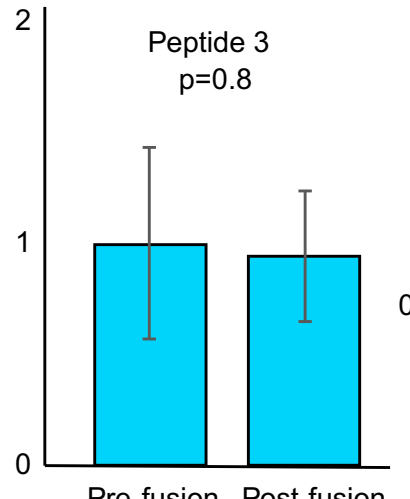

Pre-fusion Post-fusion

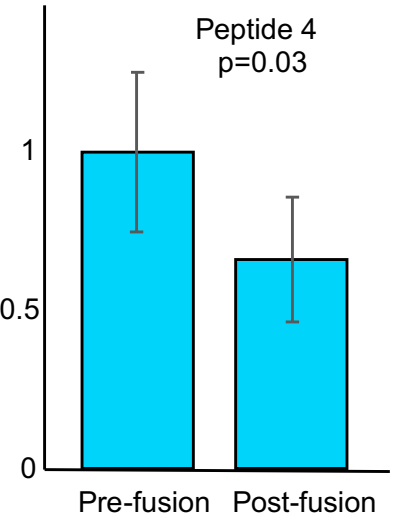

PRM quantification of the amidination ratio for Peptides 1-4 in digests of pre- or post-fusion rHA as indicated. The ratios of amidination are determined from the AUC, as measured by pseudo-PRM, for each target modified and unmodified peptide as described in Table 1. "Pre-fusion" and "post-fusion" preparations are as in Fig. 1b. SMTA amidination is performed with $20 \mathrm{mM}$ SMTA, $\mathrm{pH}$ 7.0, $30 \mathrm{~min}$ at ambient temperature. Error bars represent standard deviation. $p$ values were determined by twotailed unpaired Student's $t$ test, $n=6$ replicates prepared independently 
criteria. The three most intense transitions from the library were used for each (Table 1, Fig. 2a, b and ESM Fig. S2A, B). For normalization, we considered three internal reference peptides [25]: the equivalent unlabeled peptide with missed cleavage at the central lysine, the predicted cleavage product for the unlabeled peptide with the lysine now available for tryptic cleavage, and a peptide elsewhere in the protein generated through arginine cleavage (and hence presumably unaffected by SMTA labeling). Surprisingly, despite the inherently increased variance at missed cleavages, normalizing amidinated peptides by the fully cleaved, non-amidinated peptides yielded higher CV values (ESM Fig. S2C). Therefore, we quantified the modification ratio at each lysine by taking the ratio of the intensity of modified peptide over the intensity of unmodified peptide. SMTA concentration was set to $20 \mathrm{mM}$, the minimum value that maximized this modification ratio for any of the analyzed peptides (ESM Fig. S2D). Because we are using an ion trap to characterize three transitions in each peptide, as opposed to the Orbitrap traditionally used for parallel reaction monitoring, we describe this approach as pseudo-PRM, analogous to pseudo-SRM, when single transitions are monitored using an ion trap [25, 43]. Using this approach, we found that amidination at Peptide 1 (K62) on PR8 HA is significantly higher in the post-fusion (acid-induced) conformational state (Fig. 2c). Peptide 1 is located in the fusion $\left(\mathrm{F}^{\prime}\right)$ subdomain of HA1, far from the receptor binding site but in a region that undergoes substantial variation with fusion and that stabilizes HA2 in the pre-fusion state $[2,44]$. More modest effects were observed at Peptide 2 (K170; increased amidination) and Peptide 4 (K459; decreased amidination), with no change observed at Peptide 3 (K394) (Fig. 2c). The change in amidination in part contrasts with a previous HDX study on viral H3 hemagglutinin [2], wherein Peptide 4 was found to become far more solvent accessible upon fusion. The same study found a modest increase in solvent accessibility post-fusion for the Peptide 1 region, with little change in the vicinity of the lysines in Peptides 3 and 4. These differences could reflect differences between serotypes, or the differences between $\mathrm{D}_{2} \mathrm{O}$ accessibility and local lysine reactivity. Also, it is worthwhile to note that these peptides are chosen as reporters of the conformational change that are best suited to reaction monitoring, rather than being regions that themselves drive the fusion-associated conformational change.

To validate that the conformational switch itself drove the change in SMTA labeling, we considered two orthogonal methods of blocking viral fusion. HA requires pre-cleavage to free the fusion peptide and enable the conformational change [45]. This pre-cleavage occurs physiologically by endogenous host proteases, but can be accomplished in vitro

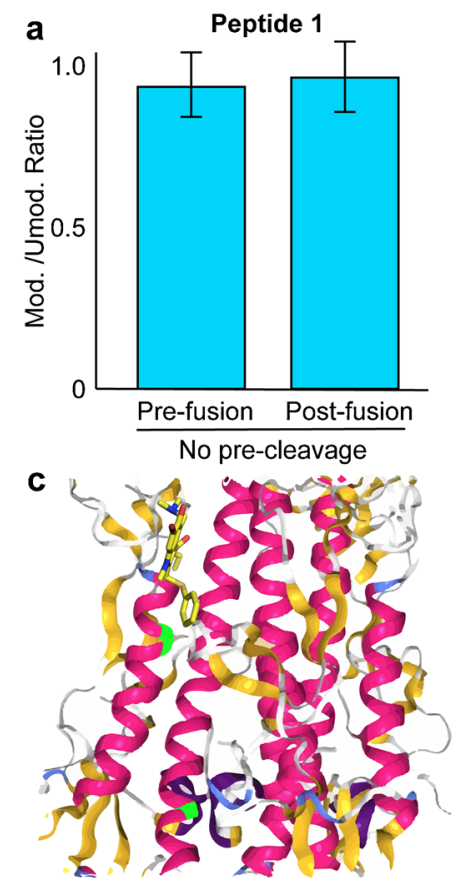

Fig. 3 The amidination assay is sensitive to conditions that interfere with viral fusion. Amidination ratios for $\mathrm{rHA}$ that has not been tryptically precleaved, subject to acidification and labeling as in Fig. 1. Amidination ratios at Peptide 1 in rHA prepared in either the pre- and post-fusion states following pre-incubation with Arbidol $(400 \mu \mathrm{M}, 30 \mathrm{~min})$, a fusion inhibitor, as indicated. "Pre-fusion" and "post-fusion" preparations are as in Fig. 1. Error bars represent standard deviation. Significance was first assessed by single factor ANOVA, followed by two-tailed Tukey's post
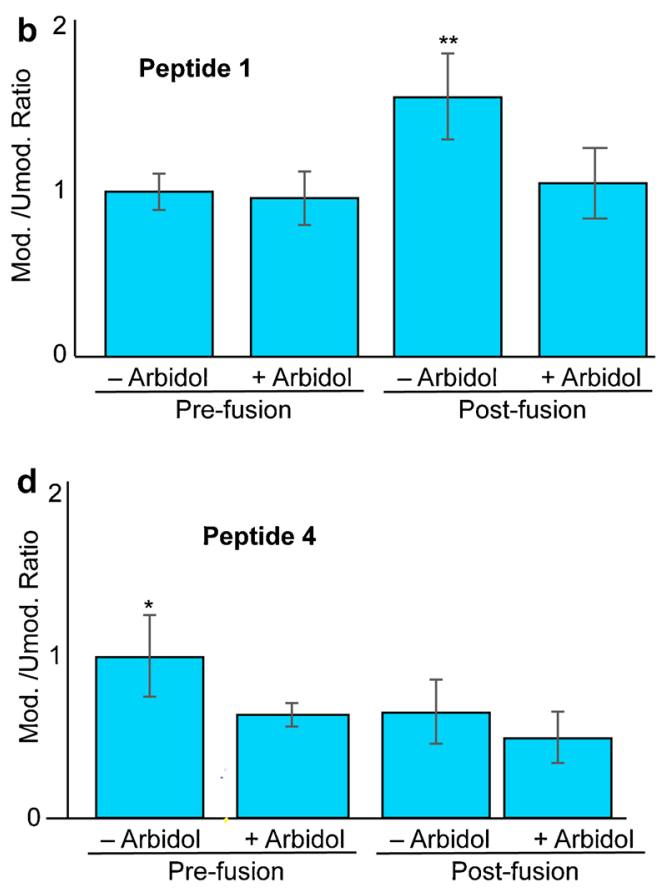

hoc test. ANOVA $\mathrm{F}=12, p<10^{-4}$, **Tukey $p<0.002 . n=6$ replicates prepared independently. Amidination ratio at Peptide 4, as described in Fig. 3b. ANOVA $F=8.3, p<10^{-3}$, *Tukey $p<0.02$. Arbidol structure superimposed in the binding pocket on a crystal structure for unbound PR8/HA, and with the amidination-prone lysines of Peptides 3 and 4 noted in green. Note that the PR8/HA structure would undoubtedly be substantially distorted, as the binding pocket on this isotype is too narrow to accommodate the inhibitor [47] 
Table 2 LODs (from standard deviation of the response) for HA peptides

\begin{tabular}{lll}
\hline Peptide & Amidination state & fmol HA \\
\hline 1 & Unmodified & 188 \\
& Modified & 178 \\
2 & Unmodified & 228 \\
& Modified & 235 \\
3 & Unmodified & 290 \\
& Modified & 252 \\
4 & Unmodified & 78 \\
& Modified & 109 \\
\hline
\end{tabular}

through brief tryptic digestion [46]. In the absence of tryptic pre-cleavage, no difference on Peptide 1 amidination of PR8 HA was observed between acidic and neutral incubation (Fig. 3a). Because of the central role of fusion in viral entry and infection, fusion inhibitors have been intensively investigated as antiviral candidates. Arbidol (umifenavir) has been reported to inhibit fusion of $\mathrm{H} 1$ serotype HA, including PR8, at $400 \mu \mathrm{M}$ [47]. We compared the amidination of target peptides in the presence or absence of arbidol, as well as under neutral or acid incubation conditions. Consistent with the amidination fingerprint serving as a reporter of fusion competence, acidification in the presence of arbidol yielded an amidination profile similar to that of HA that was never exposed to low pH in Peptide 1 (Fig. 3b). Similar, though not statistically significant (ANOVA $p=0.07$ ), effects were observed for Peptide 2 (ESM Fig. S3A). Furthermore, in support of this effect being mediated by a direct binding event, Peptides 3 and 4, which are present near the arbidol binding pocket (Fig. 3c), demonstrated decreased amidination across conditions (Fig. 3d and ESM Fig. S3B), consistent with arbidol's presence in the pocket lowering the accessibility of this residue. In summary, both biochemical and chemical inhibition of fusion yield an electrophilic footprint resembling the pre-fusion state.

\section{Sensitivity and robustness}

To determine the sensitivity of the approach, we measured the LOD for modified and amidinated Peptide 1 with respect to rHA, finding 190 and 180 fmol respectively (Table 2, Fig. 4a), with linear response up to 3 pmol. Similar LOD were identified for the other profiled peptides (Table 2, ESM Fig. S4). Although these LODs are high with respect to typical MRM and PRM thresholds, it should be stressed that these are with respect to the total HA protein concentration, rather than the levels of peptide. The amidination ratio is robust to concentration over this range (Fig. 4b). We also considered that the injection time could bias the observed ratio [25]; we maintained an AGC of $10^{4}$ while varying injection time (Fig. 4c). Longer injection times allow variance in cycle time when the AGC target is reached, while weaker signals with lower injection times can lead to measurement artifacts due to the Xcalibur
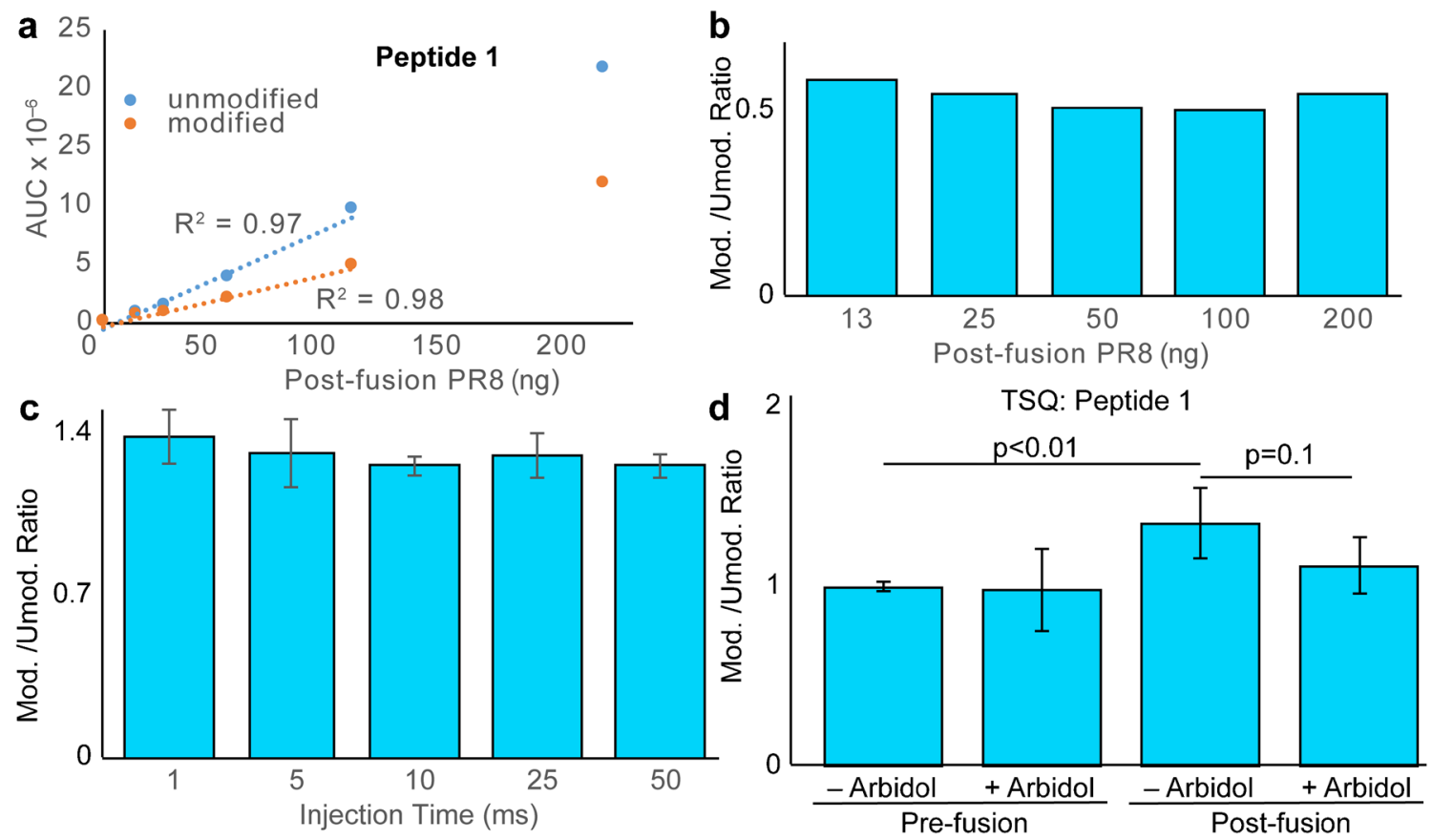

Fig. 4 Sensitivity of pseudo-PRM measurement of Peptide 1. Linear relationships between AUCs for modified and amidinated Peptide 1 and the amount of PR8 injected. Minimal dependence of the modification ratio of Peptide 1 on the amount of PR8 HA loaded between 13 and 200 ng. Minimal dependence of the modification ratio of Peptide 1 on

the injection time into the ion trap. Error bars represent standard deviation. MRM quantification of Peptide 1 in rHA digests on a triplequadrupole mass spectrometer. Significance was first assessed by single factor ANOVA, followed by two-tailed Tukey's post hoc test. ANOVA $F=6.0, p<0.005 . n=6$ replicates prepared independently 
a

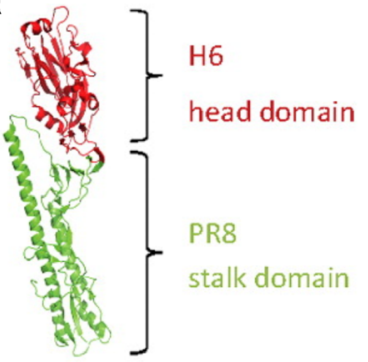

$\mathrm{cH} 6 / 1$

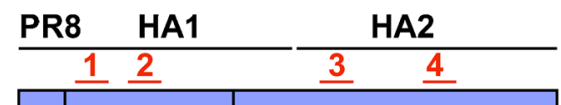

PR8 Stalk

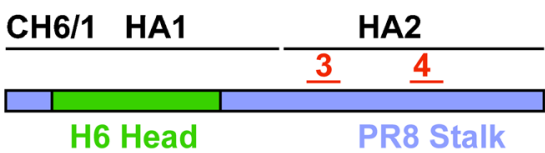

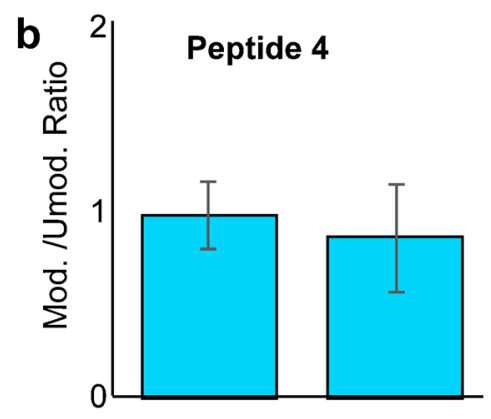

Pre-fusion Post-fusion
Fig. 5 Schematic illustrating the design of chimeric c6/1 HA, and comparison to the PR8 HA sequence. Locations of Peptides 1-4 are indicated. Peptides 1 and 2 are located in the head region of PR8 HA and hence are

noise filter [48]. Interestingly, the ratio does not change with injection time, indicating that the AGC target is not getting achieved; the cycle time is consistent across each peak. However, at lower injection times, the variance does increase. To compare to a more traditional MRM approach, we further evaluated amidination of Peptide 1 on a TSQ Quantiva triple quadrupole mass spectrometer. Similar results to those obtained using pseudo-PRM (Fig. 3b) were observed, but with greater variation (Fig. 4d).

\section{Evaluation of a mutant form of rHA}

A chimeric rHA (cHA) is a mutant form of rHA, which is composed of the head from one HA subtype and the stalk domain from the other [28]. These play an important role in emerging strategies for universal influenza vaccine development [49]. The lack of a fusion assay has limited our

a
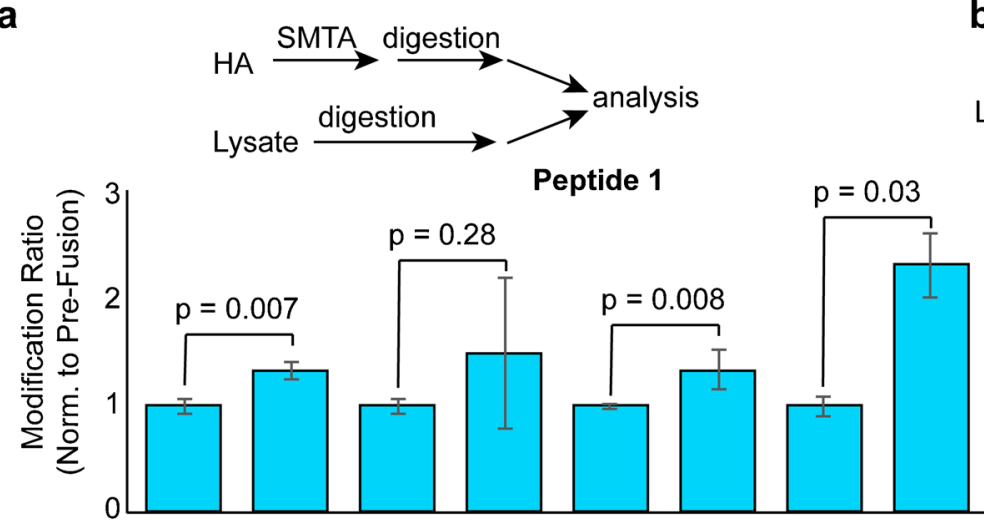

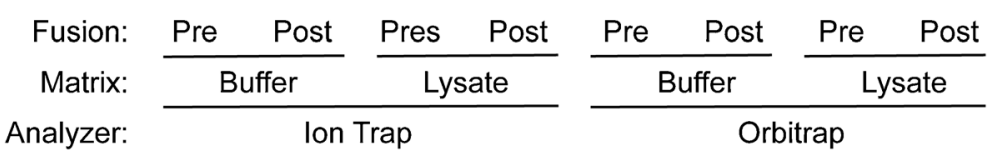

Fig. 6 Pseudo-PRM (ion trap) and PRM (orbitrap) in lysate. Differential amidination at peptide 1 on rHA in the presence or absence of tryptically digested HEK293T lysate. Error bars represent standard deviation. Significance determined from 2-tailed unpaired Student's $t$ test $(n=3$ independently prepared samples). Differential amidination of $1 \mu \mathrm{g} \mathrm{HA}$ absent in the c6/1 HA chimera. Differential amidination of Peptide 4 between pre- and post-fusion states of $\mathrm{c} 6 / 1 \mathrm{HA}$

understanding of the function of the cHA. To this end, we evaluated amidination of one such chimera, cH6/1 (Fig. 5a, b; head from A/mallard/Sweden/81/02 and stalk from A/Puerto Rico/08/34), which contains Peptide 4 in its PR8 HA stalk domain and whose virus is challenging to generate de novo, implying impaired HA function. Unlike in native PR8 HA, amidination of Peptide 4 in cH6/1 does not decrease following acidification (Fig. 5b), indicating that its conformation is less influenced by acidification, and perhaps less fusion-competent, than that of native PR8 HA.

\section{PRM for detection in complex mixtures}

Ultimately, the benefit of PRM profiling of HA fusion, as compared to HDX, would be to identify the fusionassociated conformational switch in complex biological milieu. To evaluate our methods' performance in complex
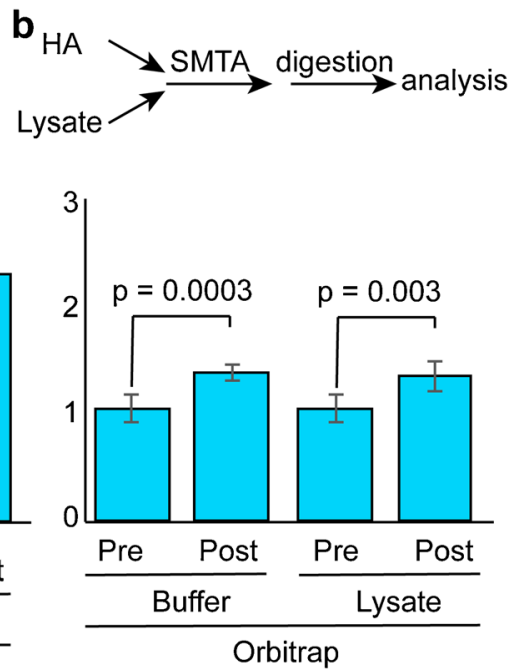

spiked into $5 \mu \mathrm{g}$ HEK293T lysate prepared by the freeze-thaw method, then SMTA-labeled, digested and analyzed by PRM in the Orbitrap. Error bars represent standard deviation. Significance determined from twotailed unpaired Student's $t$ test ( $n=6$ independently prepared samples) 
mixtures, we spiked rHA digest into a HEK293T lysate, and compared the measurement of amidination to rHA digest in buffer, as well as between the use of the LTQ ion trap and the Orbitrap (Fig. 6a). Both traps perform well, but the highresolution Orbitrap does decrease variance as opposed to the ion trap. As with the ion trap, no dependence of the modification ratio on injection time was observed (ESM Fig. S5A). Lysate added to labeled PR8 HA prior to tryptic digestion does not affect the Peptide 1 modification ratio. We also considered adding PR8 HA to the lysate prior to labeling. Interestingly, lysate prepared with high detergent RIPA buffer does affect the observed SMTA labeling, but lysate prepared by freezethaw of cells in PBS does not affect the PR8 HA modification ratios measured by PRM (Fig. 6b).

\section{Conclusions}

This study represents the first reported effort to combine electrophilic profiling and reaction monitoring. We profiled two different conformations of rHA: the pre-fusion state and the acid-induced post-fusion state. These two states demonstrate different susceptibility to electrophilic modification at lysine by the labeling reagent SMTA. The reliance of differential amidination on fusion is validated by its dependence on HA pre-cleavage and the loss of differential amidination upon preincubation with the fusion inhibitor Arbidol. Furthermore, the homogeneity of the labeling product allowed straightforward mass spectrometric quantification through MRM on a triple quadrupole instrument, pseudo-PRM in a linear ion trap, and PRM in an Orbitrap mass analyzer. Surprisingly, we find that normalization to non-amidinated peptides harboring a missed cleavage as the internal reference peptides provides robust quantification. The ability to discriminate between pre- and post-fusion states, and the robustness of the assay in the presence of complex matrix interferences, suggests that this approach will allow quantification of intracellular hemagglutinin fusion competence.

One potential application of this approach is to characterize how sequence influences HA fusion competence. Another long-term goal of this methodology is to identify HA fusion yield inside the cell. Under this scheme, we find limits of detection in the 100 to $300 \mathrm{fmol}$ range with respect to HA. At 1000 molecules of HA per virion [50], profiling cells at a multiplicity of infection of 10 would yield about 2 fmol HA in a well of a 96-well plate, above the 0.1 to 1 fmol range often achieved for peptide detection using isotope dilution MRM $[43,51]$. This method could similarly benefit from isotopically labeled standards. One inherent limitation is the constriction of peptide choice as compared to total protein quantification, wherein the peptides with the best signal, robustness, and freedom from interferences can be chosen. It is possible that in this respect, the product heterogeneity associated with more promiscuous labeling methods such as FPOP might be superior, as the diversity of products increases the number of potential precursor ions that report on individual conformational changes. On the other hand, greater diversity of products might lower the sensitivity to any individual product. Further investigations will compare amidination to other protein labeling strategies as a method to identify HA conformational changes by reaction monitoring of covalent labeling products.

Funding information This work was supported by a UCR Research and Economic Development SEED grant. Multiple reaction monitoring was performed on a TSQ Quantiva in the UCR Analytical Chemistry Instrumentation Facility, which was acquired from a NIH National Center for Research Resources grant 1S10RR022331. Molecular graphics and analyses performed with UCSF Chimera, developed by the Resource for Biocomputing, Visualization, and Informatics at the University of California, San Francisco, with the support from NIH P41-GM103311.

\section{Compliance with ethical standards}

Conflict of interest The authors declare that they have no conflict of interest.

\section{References}

1. Iuliano AD, Roguski KM, Chang HH, Muscatello DJ, Palekar R, Tempia S, et al. Estimates of global seasonal influenza-associated respiratory mortality: a modelling study. Lancet. 2018;391(10127): 1285-300. https://doi.org/10.1016/S0140-6736(17)33293-2.

2. Garcia Natalie K, Guttman M, Ebner Jamie L, Lee KK. Dynamic changes during acid-induced activation of influenza hemagglutinin. Structure. 2015;23(4):665-76. https://doi.org/10.1016/j.str.2015. 02.006.

3. Das DK, Govindan R, Nikic-Spiegel I, Krammer F, Lemke EA, Munro JB. Direct visualization of the conformational dynamics of single influenza hemagglutinin trimers. Cell. 2018;174(4):926-37 e12. https://doi.org/10.1016/j.cell.2018.05.050.

4. Webster RG, Rott R. Influenza virus a pathogenicity: the pivotal role of hemagglutinin. Cell. 1987;50(5):665-6.

5. Engen JR, Wales TE. Analytical aspects of hydrogen exchange mass spectrometry. Annu Rev Anal Chem (Palo Alto, Calif). 2015;8:127-48. https://doi.org/10.1146/annurev-anchem-062011143113.

6. Roeser J, Bischoff R, Bruins AP, Permentier HP. Oxidative protein labeling in mass-spectrometry-based proteomics. Anal Bioanal Chem. 2010;397(8):3441-55. https://doi.org/10.1007/s00216-0103471-8.

7. Kaur U, Meng H, Lui F, Ma R, Ogburn RN, Johnson JHR, et al. Proteome-wide structural biology: an emerging field for the structural analysis of proteins on the proteomic scale. J Proteome Res. 2018;17(11):3614-27. https://doi.org/10.1021/acs.jproteome. $8 \mathrm{~b} 00341$.

8. Wen J, Zhang H, Gross ML, Blankenship RE. Membrane orientation of the FMO antenna protein from Chlorobaculum tepidum as determined by mass spectrometry-based footprinting. Proc Natl Acad Sci. 2009;106(15):6134-9. https://doi.org/10.1073/pnas. 0901691106. 
9. Liu F, Meng H, Fitzgerald MC. Large-scale analysis of breast cancer-related conformational changes in proteins using SILACSPROX. J Proteome Res. 2017;16(9):3277-86. https://doi.org/10. 1021/acs.jproteome.7b00283.

10. Espino JA, Mali VS, Jones LM. In cell footprinting coupled with mass spectrometry for the structural analysis of proteins in live cells. Anal Chem. 2015;87(15):7971-8. https://doi.org/10.1021/ acs.analchem. 5 b01888.

11. Tran DT, Adhikari J, Fitzgerald MC. StableIsotope labeling with amino acids in cell culture (SILAC)-based strategy for proteomewide thermodynamic analysis of protein-ligand binding interactions. Mol Cell Proteomics. 2014;13(7):1800-13. https://doi.org/ 10.1074/mcp.M113.034702.

12. Chea EE, Jones LM. Modifications generated by fast photochemical oxidation of proteins reflect the native conformations of proteins. Protein Sci. 2018;27(6):1047-56. https://doi.org/10.1002/ pro.3408.

13. Rinas A, Jones LM. Fast photochemical oxidation of proteins coupled to multidimensional protein identification technology (MudPIT): expanding footprinting strategies to complex systems. J Am Soc Mass Spectrom. 2015;26(4):540-6. https://doi.org/10. 1007/s13361-014-1017-6.

14. Jones LM, J BS, J AC, Gross ML. Fast photochemical oxidation of proteins for epitope mapping. Anal Chem 2011;83(20):7657-7661. https://doi.org/10.1021/ac2007366.

15. Zhang H, Gau BC, Jones LM, Vidavsky I, Gross ML. Fast photochemical oxidation of proteins for comparing structures of proteinligand complexes: the calmodulin-peptide model system. Anal Chem. 2011;83(1):311-8. https://doi.org/10.1021/ac102426d.

16. Bloem E, Ebberink Eduard HTM, van den Biggelaar M, van der Zwaan C, Mertens K, Meijer AB. A novel chemical footprinting approach identifies critical lysine residues involved in the binding of receptor-associated protein to cluster II of LDL receptor-related protein. Biochem J. 2015;468(1):65-72. https://doi.org/10.1042/ bj20140977.

17. Stavenuiter F, Ebberink EHTM, Mertens K, Meijer AB. Role of glycine 221 in catalytic activity of hyaluronan-binding protein $2 . \mathrm{J}$ Biol Chem. 2017;292(15):6381-8. https://doi.org/10.1074/jbc. M116.757849.

18. Beardsley RL, Reilly JP. Quantitation using enhanced signal tags: a technique for comparative proteomics. J Proteome Res. 2003;2(1): $15-21$.

19. Liu X, Broshears WC, Reilly JP. Probing the structure and activity of trypsin with amidination. Anal Biochem. 2007;367(1):13-9. https://doi.org/10.1016/j.ab.2007.04.037.

20. Jaffee EG, Lauber MA, Running WE, Reilly JP. In vitro and in vivo chemical labeling of ribosomal proteins: a quantitative comparison. Anal Chem. 2012;84(21):9355-61. https://doi.org/10.1021/ ac302115m

21. Gau B, Garai K, Frieden C, Gross ML. Mass spectrometry-based protein footprinting characterizes the structures of oligomeric apolipoprotein E2, E3, and E4. Biochemistry. 2011;50(38):8117-26. https://doi.org/10.1021/bi200911c.

22. Zhang H, Wen J, Huang RYC, Blankenship RE, Gross ML. Mass spectrometry-based carboxyl footprinting of proteins: method evaluation. Int J Mass Spectrom. 2012;312:78-86. https://doi.org/10. 1016/j.jims.2011.07.015.

23. Zhang H, Liu H, Blankenship RE, Gross ML. Isotope-encoded carboxyl group footprinting for mass spectrometry-based protein conformational studies. J Am Soc Mass Spectrom. 2015;27(1): 178-81. https://doi.org/10.1007/s13361-015-1260-5.

24. Thumm M, Hoenes J, Pfleiderer G. S-methylthioacetimidate is a new reagent for the amidination of proteins at low $\mathrm{Ph}$. Biochim Biophys Acta. 1987;923(2):263-7. https://doi.org/10.1016/03044165(87)90012-2.
25. Sherrod SD, Myers MV, Li M, Myers JS, Carpenter KL, MacLean $\mathrm{B}$, et al. Label-free quantitation of protein modifications by pseudo selected reaction monitoring with internal reference peptides. J Proteome Res. 2012;11(6):3467-79. https://doi.org/10.1021/ pr201240a.

26. Bauer M, Ahrné E, Baron AP, Glatter T, Fava LL, Santamaria A, et al. Evaluation of data-dependent and -independent mass spectrometric workflows for sensitive quantification of proteins and phosphorylation sites. J Proteome Res. 2014;13(12):5973-88. https:// doi.org/10.1021/pr500860c.

27. Federspiel JD, Codreanu SG, Goyal S, Albertolle ME, Lowe E, Teague J, et al. Specificity of protein covalent modification by the electrophilic proteasome inhibitor carfilzomib in human cells. Mol Cell Proteomics. 2016;15(10):3233-42. https://doi.org/10.1074/ mcp.M116.059709.

28. Hai R, Krammer F, Tan GS, Pica N, Eggink D, Maamary J, et al. Influenza viruses expressing chimeric hemagglutinins: globular head and stalk domains derived from different subtypes. J Virol. 2012;86(10):5774-81. https://doi.org/10.1128/JVI.00137-12.

29. Chevallet M, Luche S, Rabilloud T. Silver staining of proteins in polyacrylamide gels. Nat Protoc. 2006;1(4):1852-8. https://doi.org/ 10.1038/nprot.2006.288.

30. Tscherne DM, Manicassamy B, Garcia-Sastre A. An enzymatic virus-like particle assay for sensitive detection of virus entry. $\mathrm{J}$ Virol Methods. 2010;163(2):336-43. https://doi.org/10.1016/j. jviromet.2009.10.020.

31. White KM, De Jesus P, Chen Z, Abreu P Jr, Barile E, Mak PA, et al. A potent anti-influenza compound blocks fusion through stabilization of the prefusion conformation of the hemagglutinin protein. ACS Infect Dis. 2015;1(2):98-109. https://doi.org/10.1021/ id500022h.

32. $\mathrm{Xu} \mathrm{T}$, Park SK, Venable JD, Wohlschlegel JA, Diedrich JK, Cociorva D, et al. ProLuCID: an improved SEQUEST-like algorithm with enhanced sensitivity and specificity. J Proteome. 2015;129:16-24. https://doi.org/10.1016/j.jprot.2015.07.001.

33. Cociorva D, D LT, Yates JR. Validation of tandem mass spectrometry database search results using DTASelect. Curr Protoc Bioinformatics. 2007; Chapter 13:Unit 13 4. https://doi.org/10. 1002/0471250953.bi1304s16.

34. Brunner J, Zugliani C, Mischler R. Fusion activity of influenza virus PR8/34 correlates with a temperature-induced conformational change within the hemagglutinin ectodomain detected by photochemical labeling. Biochemistry. 1991;30(9):2432-8.

35. Wiley DC, Wilson IA, Skehel JJ. Structural identification of the antibody-binding sites of Hong Kong influenza haemagglutinin and their involvement in antigenic variation. Nature. 1981;289(5796):373-8.

36. Wilson IA, Skehel JJ, Wiley DC. Structure of the haemagglutinin membrane glycoprotein of influenza virus at 3 a resolution. Nature. 1981;289(5796):366-73.

37. Chen J, Lee KH, Steinhauer DA, Stevens DJ, Skehel JJ, Wiley DC. Structure of the hemagglutinin precursor cleavage site, a determinant of influenza pathogenicity and the origin of the labile conformation. Cell. 1998;95(3):409-17. https://doi.org/10.1016/S00928674(00)81771-7.

38. Weis WI, Brunger AT, Skehel JJ, Wiley DC. Refinement of the influenza-virus hemagglutinin by simulated annealing. J Mol Biol. 1990;212(4):737-61. https://doi.org/10.1016/0022-2836(90) 90234-D.

39. Bullough PA, Hughson FM, Skehel JJ, Wiley DC. Structure of influenza haemagglutinin at the $\mathrm{pH}$ of membrane fusion. Nature. 1994;371(6492):37-43. https://doi.org/10.1038/371037a0.

40. Rose AS, Bradley AR, Valasatava Y, Duarte JM, Prlić A, Rose PW, et al. NGL viewer: web-based molecular graphics for large complexes. Bioinformatics. 2018;34(21):3755-8. https://doi.org/10. 1093/bioinformatics/bty419. 
41. Giansanti P, Tsiatsiani L, Low TY, Heck AJR. Six alternative proteases for mass spectrometry-based proteomics beyond trypsin. Nat Protoc. 2016;11(5):993-1006. https://doi.org/10.1038/nprot.2016. 057.

42. Liebler DC, Zimmerman LJ. Targeted quantitation of proteins by mass spectrometry. Biochemistry. 2013;52(22):3797-806. https:// doi.org/10.1021/bi400110b.

43. Abbatiello SE, Mani DR, Schilling B, MacLean B, Zimmerman LJ, Feng XD, et al. Design, implementation and multisite evaluation of a system suitability protocol for the quantitative assessment of instrument performance in liquid chromatography-multiple reaction monitoring-MS (LC-MRM-MS). Mol Cell Proteomics. 2013;12(9):2623-39. https://doi.org/10.1074/mcp.M112.027078.

44. Chen J, Wharton SA, Weissenhorn W, Calder LJ, Hughson FM, Skehel JJ, et al. A soluble domain of the membrane-anchoring chain of influenza virus hemagglutinin (HA2) folds in Escherichia coli into the low-pH-induced conformation. Proc Natl Acad Sci U S A. 1995;92(26):12205-9. https://doi.org/10.1073/pnas.92.26.12205.

45. Garten W, Bosch FX, Linder D, Rott R, Klenk HD. Proteolytic activation of the influenza-virus hemagglutinin - the structure of the cleavage site and the enzymes involved in cleavage. Virology. 1981;115(2): 361-74. https://doi.org/10.1016/0042-6822(81)90117-3.

46. Klenk HD, Rott R, Orlich M, Blodorn J. Activation of influenza-A viruses by trypsin treatment. Virology. 1975;68(2):426-39. https:// doi.org/10.1016/0042-6822(75)90284-6.
47. Kadam RU, Wilson IA. Structural basis of influenza virus fusion inhibition by the antiviral drug Arbidol. P Natl Acad Sci USA. 2017;114(2):206-14. https://doi.org/10.1073/pnas.1617020114.

48. Savitski MM, Sweetman G, Askenazi M, Marto JA, Lang M, Zinn $\mathrm{N}$, et al. Delayed fragmentation and optimized isolation width settings for improvement of protein identification and accuracy of isobaric mass tag quantification on Orbitrap-type mass spectrometers. Anal Chem. 2011;83(23):8959-67. https://doi.org/10.1021/ ac201760x.

49. Krammer F, Pica N, Hai R, Margine I, Palese P. Chimeric hemagglutinin influenza virus vaccine constructs elicit broadly protective stalk-specific antibodies. J Virol. 2013;87(12):6542-50. https://doi. org/10.1128/jvi.00641-13.

50. Vahey MD, Fletcher DA. Low-fidelity assembly of influenza a virus promotes escape from host cells. Cell. 2019;176(1-2):281$94 \mathrm{e} 19 . \mathrm{https} / / /$ doi.org/10.1016/j.cell.2018.10.056.

51. Addona TA, Abbatiello SE, Schilling B, Skates SJ, Mani DR, Bunk $\mathrm{DM}$, et al. Multi-site assessment of the precision and reproducibility of multiple reaction monitoring-based measurements of proteins in plasma. Nat Biotechnol. 2009;27(7):633-U85. https://doi.org/10. 1038/nbt.1546.

Publisher's note Springer Nature remains neutral with regard to jurisdictional claims in published maps and institutional affiliations. 